\title{
The Outcomes of Workshop for Introduced View of Nature of Science to Vietnamese Science Teachers in Mekong Delta Region of Vietnam
}

\author{
Chokchai Yuenyong \\ Thi Phuong Thao-Do \\ Faculty of Education, Khon Kaen University, Thailand \\ Email: ychok@kku.ac.th,
}

Doi:10.5901/mjss.2015.v6n2p599

\begin{abstract}
We presented here our study on Vietnamese teachers and pre-service teachers' view of nature of science (NOS) and some practical training activities that we used to develop their understanding of NOS. Results were taken from our workshop about nature of science (NOS) and science - technology - society (STS) approach at Can Tho University, Vietnam on 20 March 2013. Participants are around 30 Vietnamese lecturers and pre-service teachers of Can Tho university and 32 participants from Khon Kaen University. This workshop was funded by the project of KKU Science Education Mekong Technology Transfer that organized by science education program, Faculty of Education, Khon Kaen University. The purpose of the workshop was to introduce the recently focused education goal about the nature of science of science education worldwide and the STS approach to Vietnamese educators and teachers. This training workshop was conducted based on the constructivist lens where the prior knowledge and experience of the participants were employed to let them construct the concepts of nature of science by themselves through various activities. Reflections and discussion indicated that Vietnamese participants currently have some certain understanding as well as naïve conceptions about the nature of science. Most of the misconceptions were successfully transformed to the informed ones through the workshop except the idea of the function of, and relationship between theory and law'. We also reported here the ineffectiveness of the VNOS-C of Lederman et al. (2002) in collecting Vietnamese conceptions about NOS. We discussed some possible reasons for this unsuccessfulness. Several suggestions for future researches on Vietnamese teachers' understanding and thinking and for the next training workshops or training programs in Vietnam were made.
\end{abstract}

Keywords: nature of science $\bullet$ Vietnamese teachers $\bullet$ constructivist $\bullet$ VNOS-C

\section{Introduction}

In science teaching, what, how and how much of NOS should be integrated in the science curriculum of each country cannot be a benchmark for everyone due to the influences of culture and society on assumptions about NOS and the roles of NOS in science learning. NOS, although has been endorsed as an important learning goal in science education in many countries worldwide, is not popular in every country. Typically, NOS is a new notion and currently is not considered a compulsory learning outcome in Vietnam. Therefore, there are many questions such as "what is the picture of NOS in Vietnam?", "is there any NOS currently in Vietnamese science curriculum", "should NOS be taught in Vietnamese school?", "how and how much NOS should be taught in Vietnamese school?" that should be addressed. Since NOS refers to the values and assumptions inherent to scientific knowledge and the development of scientific knowledge (Lederman \& Lederman, 2004), certainly there are implicit messages of NOS integrated in Vietnam's science curriculum. Unfortunately, research already pointed out that implicit approach is less effective in constructing informed views of NOS (Khishfe \& Abd-El-Khalick, 2002). Being presented here are Vietnamese teacher educators and pre-service teachers' view of NOS. The main framework of the NOS elements used in this study is from the 8 NOS aspects (including the 'no single universal method') of Lederman (2007).

Through a study on constructivist learning environment at Can Tho university, Vietnam in October 2012 (Thao-Do, Bac-Ly and Yuenyoung, 2014 - in press), the authors found that the term 'nature of science' is totally foreign for Vietnamese teachers and students although the nature of science has been considering an advanced and important goal of science learning in many countries. We therefore organized a workshop to introduce this direction of teaching, learning and research for Vietnamese teachers, particularly for teachers from School of Education, Can Tho University, Vietnam. We presented here Vietnamese teachers and pre-service teachers' view of nature of science (NOS) and some practical 
training activities that we used to develop their understanding of NOS.

\section{Methodology}

This study employs an interpretive paradigm to report Vietnamese teacher educators and pre-service teachers' view of nature of science (NOS) and of NOS teaching. Data were taken from a prolong investigation using several methods for data triangulation including questionnaire survey, observation, discussion and interview. Participants are science teacher educators and student teachers of School of Education, Can Tho University, a state university in Mekong Delta region, Vietnam.

\subsection{Participants}

Participants in Vietnam are around 30 lecturers and student teachers from 3 departments of Science Education (Biology, Chemistry, and Physics) of the School of Education, Can Tho university, Vietnam. Each department sent 4 lecturers and around 6 students to attend the workshops. The science lecturers have very different teaching experience, from the first year to the 25 years of teaching experience. The students are from the last year of university bachelor degree program (year 4) in science education and are currently practicing teaching in real situations at upper secondary schools in Can Tho city and Mekong Delta region.

Participants in Thailand are 32 lecturers and PhD and Master students from Khon Kaen university, Thailand, including 3 lecturers, $4 \mathrm{PhD}$ students and 25 Master students from different years of Science Education program. Because the Science Education program in Thailand does study the roles of the nature of science in science teaching, the majority of Thai students had some certain understanding of NOS. This study therefore focused on the Vietnamese NOS only. Thai participants took place in discussion and activities together with Vietnamese participants for knowledge and culture sharing as well as to enhance the collaboration between two countries. We assigned the discussion groups of about 10 members from both countries for these purposes.

Almost all of the Vietnamese and Thai participants can use English for communication at intermediate level or upper. However, to make sure our ideas were fully understandable for the Vietnamese participants, bilingual English and Vietnamese were used during the entire workshop. A lecturer from the Department of Foreign Languages, Can Tho university was assigned to be the Vietnamese translator of the workshop. Noted that the second author is a Vietnamese and a lecturer of Can Tho university along with being a PhD student of Khon Kaen university. Therefore, the translation was ensured by two translators. At some certain points, Thai language was also used by the first author and the Thai participants to make clear several questions, answers, and ideas.

\subsection{Instrument}

We used a revised version of View of Nature of Science questionnaire form C (VNOS-C) which was originally developed by Lederman et al. (Lederman et al. 2002) to do the pre-test at the beginning of the workshop and online through the survey site SurveyMonkey (https://www.surveymonkey.com). The slightly revised version of VNOS-C that made by Goff et al. (2012) was used in which the question about 'species' was replaced by the question of 'element' because in Vietnam, the concept 'element' is more familiar with Vietnamese than the concept 'species'. Grade 8 Vietnamese lowersecondary students start to study about element (Trong, Cuong, and Hien 2003-2012 Vietnamese Chemistry textbook grade 8) then use this concept in numerous chemistry lessons, until they finish their upper secondary school. On the other hand, the concept of species is taught only in grade 12 upper- secondary schools (Dat et al. 2007-2012 Vietnamese Biology textbook grade 12).

However, there are only 7 participants fulfill all the ten items of the questionnaire, from both online and paper in which 1 response cannot be used because the participant search the internet for the answers instead of sharing her own voice. We hence analyzed 6 forms that show the participants' view and the responses during the workshop only. The reasons why this form did not work on Vietnamese teachers and pre-service teachers will be discussed later in the discussion part and we therefore suggested several ways to gather Vietnamese teachers' and students' opinions about nature of science for future researches.

\subsection{Workshop activities and tasks}

This workshop about Nature of science of the project of KKU Science Education Mekong Technology Transfer that run by 
science education program, Faculty of Education, Khon Kaen University. The workshop was held in one day with two sections in total 6 hours. The morning section from 9:00 - 12:00 was to introduce the concepts of NOS for Vietnamese teachers and pre-service teachers. The afternoon section from 13:00 - 16:00 was to introduce the STS approach and its application in teaching NOS. A 15 minutes coffee break was provided at the middle of each section. This paper reported the results from the morning section only, to focus on Vietnamese teachers and pre-service teachers' views of NOS.

We used the constructivist lens for designing activities and discussion questions to let the participants reflect and construct the concepts of NOS by themselves. The tasks range from some quick tasks (e.g., observe a video clip, then give feedback or reflections on that clip) to the ones that need discussions and collaborations among the participants. Guide and reflective questions were made to help the participants focus on the nature of science and scientific activities. After the participants already confirmed their concepts or change from the naïve concepts to the informed ones, brief conclusions after each activity were made to review their concepts.

The ideas of NOS for our tasks are from different sources, but mostly from Lederman and his colleagues (Lederman et al. 2002; Lederman 2007) and McComas and his colleagues (McComas 1996; McComas, Almazroa, and Clough 1998). Table 1 summarizes the activities and the main discussion questions for each activity that we used to let the participants construct the aspects of NOS. Expected NOS goals were also shown in this table. The original sources noted at the end of the table were recommended to look for more details. The results from these activities will be discussed later in the discussion part.

Along with those activities, discussion questions about other issues were used to balance time and content for the workshop. There are these main discussion questions:

Q1: What is science? What is not science? examples.

Q2: Do you think that there is a universal - step by step scientific method? Please share your ideas with specific

Q3: What is the function of a law? What is the function of a theory? Are there differences and/or similarities between law and theory? implicit?

Q4: Can you find some aspects of NOS embedded in your science teaching? What are they? Are they explicit or

Moreover, we presented the ideas of Brosnowski (1973) about scientific uncertainty by showing a man's face through different observational devices (figure 1) to show that one particular thing will look different through different instruments and the same thing might happen for scientific pictures: different through different views.

Figure 1: A man's face through different observational devices - presents the ideas of 'no absolute knowledge'
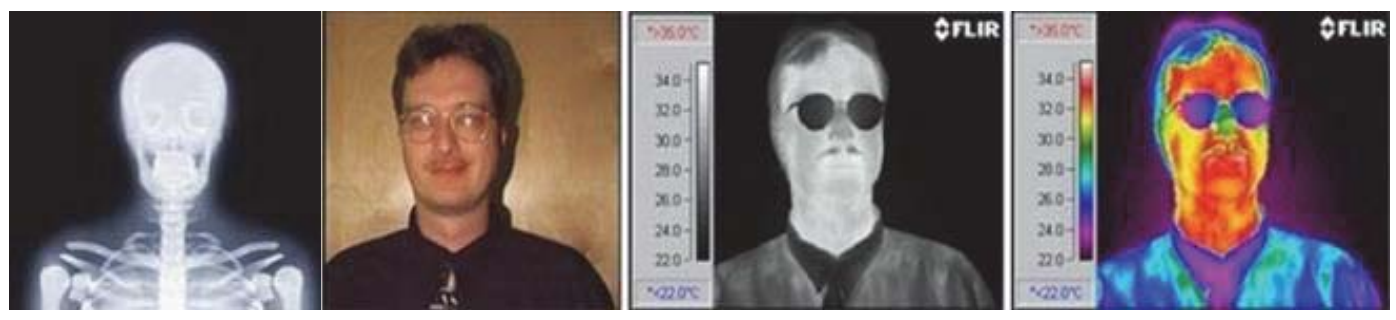

Last, Einstein's famous quotation about logic and imagination was used to discuss the role of imagination and creativity in doing science.

"Logic will get you from A to B. Imagination will take you to everywhere." (Albert Einstein).

Results from these activities and discussions will be presented later in the next part.

Table 1: Workshop activities

\begin{tabular}{|c|c|c|}
\hline Activities and description & Discussion and reflective questions & NOS aspect(s) \\
\hline $\begin{array}{l}\text { A1: 'You can't trust science' } \\
\text { The participants watch a video clip which } \\
\text { presents the changes in scientific knowledge } \\
\text { about the shape of the earth. }\end{array}$ & $\begin{array}{l}\text { Do you agree with the message } \\
\text { presented in this video clip or not? Why } \\
\text { or why not? }\end{array}$ & $\begin{array}{l}\text { Scientific knowledge while durable, has a } \\
\text { tentative character }\end{array}$ \\
\hline
\end{tabular}




\begin{tabular}{|c|c|c|}
\hline $\begin{array}{l}\text { A2: 'Conflicting theories for the origin of } \\
\text { the Moon' } \\
\text { Based on the provided scientific evidences } \\
\text { and the } 4 \text { theories, the participants were } \\
\text { asked to draw their inferences from the } \\
\text { evidences and then choose the theory which } \\
\text { they support. }\end{array}$ & $\begin{array}{l}\text { Which aspects of NOS did you find } \\
\text { through this activity? }\end{array}$ & $\begin{array}{l}\text { - Science is an attempt to explain natural } \\
\text { phenomena } \\
\text { - Scientific knowledge is empirically-based } \\
\text { - Scientific knowledge relies heavily, but } \\
\text { not entirely, on observation, experimental } \\
\text { evidence, rational arguments, and } \\
\text { skepticism } \\
\text { - Scientific knowledge is subjective }\end{array}$ \\
\hline $\begin{array}{l}\text { A3: 'Introduction to the quantum theory' } \\
\text { A participant was asked to give a brief } \\
\text { introduction to the quantum theory in which } \\
\text { he mentioned the previous theories before } \\
\text { the quantum theory and some explanations. }\end{array}$ & $\begin{array}{l}\text { How can you understand the quantum } \\
\text { theory if you study it solely, without other } \\
\text { (previous) theories? }\end{array}$ & $\begin{array}{l}\text { Scientific knowledge is theory-laden: } \\
\text { Everything one observes is interpreted } \\
\text { through a prior understanding of other } \\
\text { theories and concepts. }\end{array}$ \\
\hline $\begin{array}{l}\text { A4: 'Card activity - Establishing priorities } \\
\text { for solving problems' } \\
\text { The participants discussed, argued among } \\
\text { their group about the importance and priority } \\
\text { of } 6 \text { different research topics to find the 'most } \\
\text { important' topic for their group. }\end{array}$ & $\begin{array}{l}\text { What do you think is most important for } \\
\text { scientists to focus on immediately? }\end{array}$ & $\begin{array}{l}\text { Science is socially and culturally } \\
\text { embedded }\end{array}$ \\
\hline $\begin{array}{l}\text { A5: 'Impossible motion' } \\
\text { Watch a part of a video clip about an } \\
\text { 'impossible motion' and make observation } \\
\text { and inference. } \\
\text { After that, watch the rest of that clip to see } \\
\text { what happens at different direction. }\end{array}$ & $\begin{array}{l}\text { What can you observe? } \\
\text { What can you infer? }\end{array}$ & $\begin{array}{l}\text { The distinction between observations and } \\
\text { inferences } \\
\text { - Observation is the process through which } \\
\text { the basic facts of science are acquired } \\
\text { - Inference is the act of drawing a } \\
\text { conclusion based on observations and } \\
\text { previous knowledge. }\end{array}$ \\
\hline
\end{tabular}

Noted: A1 used the clip 'You can't trust science' (TheThinkingAtheist 2010).

A2 used an adaptation of the Nature of Science Teaching Activities from Science Online - Te Kete Ipurangi (Norton et al. Science Online - Te Kete Ipurangi: Conflicting theories for the origin of the Moon).

A4 used an adaptation of the Nature of Science Teaching Activities from Science Online - Te Kete Ipurangi (Norton et al. Science Online - Te Kete Ipurangi: Establishing priorities for solving problems).

A5 used the clip 'Impossible motion: magnet-like slopes' (Thelllusioncontest 2010).

These activities are mainly belongs to Physics because the two authors are both Physics lecturers.

\section{Results and Discussions}

\subsection{Results from the questionnaire:}

As noted before, 6 fully responses for the 10 VNOS questions were analyzed based on the methods used by Lederman et al. (2002), Schwartz et al. (2004), and Goff et al. (2012). Because we did not follow up by interviewing the participants to get more information and make clear the ideas, we clarify the responses broadly into two categories only as 'more naïve view' and 'more informed view' similar to the examples provided by Lederman at el. (2002). Noted that there are several answers which we did not categorized because they are too short and/or general to exhibit the authors' view of NOS. We reported here Vietnamese views of NOS from each questions instead of summarizing their views on each aspect of NOS. We expected that the way Vietnamese assume about science and nature of science from each question will give several hints to develop a more suitable VNOS-C questionnaire for the context of Vietnam.

\subsubsection{VNOS-C1: What is science? What makes science different from other disciplines of inquiry?}

4 participants showed a more informed view about science when they regarded science to a body of knowledge, a process of inquiry and scientific method, or to the roles of science in human development. However, each of them mentioned from 1 to 2 of the above aspects of science only. One participant did not regard science to the above ideas but to its tentativeness and creativity characteristics when she said: "Science is an ology that always has change and creativity".

Only one participant has an unclear view as he supposed "Science is a field of study describes the laws of the natural world and society that any individual must follow it. The distinctive characteristics of science with other areas are that we cannot change the rules that govern any phenomena". 


\subsubsection{VNOS-C2: What is an experiment?}

4 participants focused on the purposes of experiment as they said experiment is an activity to: 1) prove something (statement, theory, law etc.); 2) investigate a certain phenomenon; 3) reproduce a phenomenon or demonstrate a theory or law. One participant related experiment to its process when he said: "Experiment is manipulates which create the phenomenon, observe the phenomenon and explain the phenomenon." The other wrote very generally: "Is human activities in order to find the laws of nature."

From these responses, it is difficult to imply about the participants' view of NOS without followed-up interview as most of them display the general goals of experiment but did not show the depth understanding. As recommended earlier, this question should be used for interview together with the followed in-depth questions.

\subsubsection{VNOS-C3: Does the development of scientific knowledge require experiments?}

5 of the 6 participants indicated the more naïve view on scientific method when they believed that the development of scientific knowledge necessarily require experiments. For an example, one wrote: "Yes. Experiment is a clear evidence to prove a point of view or consideration is true or false, which led to the expansion of knowledge."

There is only one participant shared the more informed view of NOS as he wrote: "Experiment plays an important role for the development of science. However, there is new knowledge built from the theoretical foundation, because in reality, scientists cannot always conduct a set of experiments. For examples: the theory of relativity, fusion reactions." From this response, we can also found the idea of theory-laden.

\subsubsection{VNOS-C4: If you believe that science reflects social and cultural values, explain why. If you believe that science is universal, explain why.}

For this question, 3 participants showed more informed views on the social and cultural aspect of NOS when the other 3 indicated that science is universal. Moreover, this question also can investigate Vietnamese participants' view on the tentativeness of scientific knowledge when some of them presented the changes in knowledge under the urge of society and culture.

Responses to defend the social and cultural characteristic of science are: "At first, science is affected by social and cultural values. However, since science has its correctness characteristic, science gradually moves to the universal quality.", "science is not something absolute", and "For example, before the Renaissance, the church considered that the earth was the center of the universe..."

On the other hand, participants whom defend the universal science used these arguments: "The non-boundaries characteristic of science...", "scientific truth will be proved" and "science is a knowledge-system which has been verified experimentally."

\subsubsection{VNOS-C5: After scientists have developed a scientific theory, does the theory ever change?}

It seems that the tentativeness of scientific knowledge is not a challenge for Vietnamese teachers as all of the 6 participants showed a more informed view on this aspect. For example, one wrote: "Scientific theories will have to change. Since there are scientific problems in which people do not have enough knowledge that will lead to the wrong views. An example is the change of the atomic model over time." The other explained "Learning the changed theories to see their development and fundamentals from which the theory developed."

\subsubsection{VNOS-C6: Is there a difference between a scientific theory and a scientific law?}

On the other hand, the next issue about the function and relationship between theory and law is really a challenge for our participants, where 5 over 6 participants showed the more naïve view in which 1 wrote "don't know" in the answer. The remaining participant also did not show deep informed view of this aspect when she wrote briefly: "Theory is different from law. Law has higher accuracy than theory."

Very typical misconceptions about this aspect of NOS were showed here. For example:

- " "Theory is a problem that has not been proven precisely."

- " "Law is a problem that has been proven and recognized."

- " "Theories can become laws when they have been proven." 
- " "Scientific theories can be adjusted and laws are not."

Obviously from this, this NOS feature should gain more attention from educators in science teacher training programs in Vietnam.

\subsubsection{VNOS-C7: How certain are scientists about the structure of the atom? What specific evidence do you think} scientists used to determine what an atom looks like?

5 participants indicated that "Scientists are completely certain" thanks to "experiments" and "atom photograph". The last one indicated a more informed view about scientific uncertainty when he wrote "The development of science is currently stopping at revealing the images and nature of the individual atoms. However, the detailed atomic structure still stops at the theoretical models..." All responses did not regard to the imagination and creativity feature of NOS as suggested by Lederman et al. (Lederman et al. 2002) without followed up interview.

3.1.8 VNOS-C8: How certain are scientists about their characterization of what an element is? What specific evidence do you think scientists used to determine what an element is?

Similar to VNOS-C7, and as mentioned previously, VNOS-C8 did not expose much more ideas about NOS than what we had from VNOS-C7. The difference lies on the shorter response and less evidence than VNOS-C7. Three of the participants gave very brief answer. One did not answer the question. Only two of them provided their supporting ideas for the assumption.

3.1.9 VNOS-C9: How are different conclusions possible if scientists in both groups have access to and use the same set of data to derive their conclusions?

This question results in different ways of explanation. However, 3 participants shared the same idea of subjective-NOS. For example, one wrote: "Because science is relative and subjective. They are based on different assumptions. They felt that the hypothesis is correct and appropriate, and then they accept."

The others relate to the matter of evidence in empirical NOS and scientific method: "Because of the limitations of the development of science at the present time, there is the lack of accurate data to determine which theory is completely correct." or "Because for a phenomenon, there are many ways to explain. Must find more data to eliminate other explanations."

Roles of imagination and creativity did not appear in the explanations. However, we supposed that the followed up interview can do this job.

3.1.10 VNOS-C10: Scientists perform experiments/investigations when trying to find answers to the questions they put forth. Do scientists use their creativity and imagination during these investigations?

5 of 6 participants agree that scientists must use their imagination and creativity. However, most of them think that these characteristics of scientists should be used in the 'planning and designing stages' only. Just one participant thought that scientists must use their imagination and creativity throughout the research, from "establishment of ideas", "collect data", until "after data collection, solving difficult problems..." The other participant believed that "Science is correct, a collection of facts and science explains the phenomenon in a convincing way, cannot be imagination."

\subsection{Questionnaire result summary}

None of the Vietnamese participants currently has a full understanding of NOS. VNOS-C1 and VNOS-C10 successfully revealed the participants' conceptions about science and the roles of imagination and creativity in doing science. VNOSC2 'what is an experiment' showed some certain understanding of the participants about experiment and its roles yet did not reveal much information about view of NOS. Fortunately, VNOS-C3, as the following question of VNOS-C2, notified the naïve view on a 'universal' scientific method from most of the Vietnamese participants (5 out of 6 ). VNOS-C5 showed that all of the participants believe in the tentativeness of scientific knowledge however they did not hold a firm view when VNOS-C7 and VNOS-C8 revealed that most of them still believe that the current knowledge about 'atoms' and/or 'element' are complete certainty. VNOS-C9 did not show all of its ability to relate to multi aspects of NOS, particularly the creativeness NOS as our expectation. The issues that hold most of Vietnamese naïve conceptions are 'social and culture 
aspect of NOS' and 'the function and relationship between theory and law' were presented by VNOS-C4 and VNOS-C6.

\subsection{Results from the workshop}

The discussion parts also confirmed the similar concern as in the questionnaire when none of the Vietnamese participants demonstrated a fully understanding of the nature of science. Most of them made some common misconceptions about theory and law, imagination and creativity, social and cultural NOS and the 'universal' scientific method. However, the other NOS aspects such as tentativeness NOS, empirical based NOS, the difference and relationship between observation and inference are at more informed level and gained support from most of the participants.

Most of the activities presented in the previous part 'Workshop activities and tasks' worked well on the workshop and achieved its purposes. We therefore presented here the most noticeable results only. With $A 1$, most of the participants agree that science has its bias and science will change. We then asked them if science will certainly change, why we do science. They confirmed that science is the most reliable field as it was based on evidences, facts and rational arguments. The change in science does not demonstrate that science is unreliable but demonstrates its development. The demonstration about 'no absolute knowledge' (figure 1) worked very well as the participants later regarded it in their discussion several time.

We then discuss some important ideas about 'what is science' and 'what is not science' (Q1), the main ideas that we would like to let the participants think of is that science is: 1) a body of knowledge, 2) method, and 3) Way of knowing (Lederman 2007). In general, the participants answered in the two first categories. These 'non-NOS' aspects were presented in the discussion: 1) Able to solve all problems, 2) Certain or absolute, 3) A search for truth. The ideas came from the 'ten myths of science' as noticed by McComas (1996). A small discussion about 'truth' or 'perception' was made during this main question.

Q2 showed an interesting issue that may relate to Thai and Vietnamese educational culture, therefore, we decided to report here. After discussion in groups, most of the Vietnamese participants supported the NO-universal step by step scientific method yet some Thai participants said that there is a universal one. They regarded the common 5-steps scientific method which starts from making an observation - asking a question - forming a hypothesis - conducting an experiment - and finally accepting or rejecting the hypothesis. However, they emphasized that the order of the steps could be change as well as we may repeat the cycle until we find the right answers. We supposed that there is this difference between the two countries because the teaching and learning style in Thailand and Vietnam has some differences. For instance, Thai teachers and students get used with more models in teaching and learning, such as the 5Es teaching cycle. This job may form the stiff thinking in Thai teachers and students. On the other hand, Vietnamese teachers are free in using different pedagogical content knowledge (PCK) for their lesson plans and teaching. Although almost all of Vietnamese schools and teachers must follow the national curriculum proposed by the Ministry of Education and Training (MOET), they can choose the suitable teaching methods or models for their classes. No models were introduced as the 'best'. As a result, a variety of teaching, learning and research methods are used in Vietnam and form a more flexible idea in the scientific method.

The activity A2-'Conflicting theories for the origin of the Moon' resulted in more promising conclusions about science and nature of science than what the authors expected. Besides the expected NOS goals, the participants also regarded to scientists' imagination, scientific method to answer our question. However, this activity cost the most of time for activities.

The card activity A4-'Establishing priorities for solving problems' also clearly expressed the social and cultural impact on science and well demonstrated the subjective-NOS. Different responses of the participants from the two countries Thailand and Vietnam, from different groups of age, and from different majors excellently exhibited those ideas. For an example, young participants tended to focus on technology and its negative effect as they picked the card "Find out whether mobile phones cause damage to the brain" because they thought "mobile phones is everywhere around you...". On the other hand, the older participants chose the card "Provide clean drinking water for people in watershortage areas" because they though "water is life. And life is the most valuable thing."

Although the participants come up agreement with most of the aspects of NOS which were presented, there are some debates about the distinction between theory and law (Q3). In particular, some teachers confirmed that laws will become theory and/or theory will become law if we have more supporting evidence. Most of them declared that law is "truer" than theory and theories will easier to be changed than laws. They used the diagram about the levels of scientific generalization to support their idea (figure 2). It seems that, unfortunately, this diagram can lead to the misconception that a theory will become a law. We therefore suggested that more care should be paid when using this figure in teaching 
science.

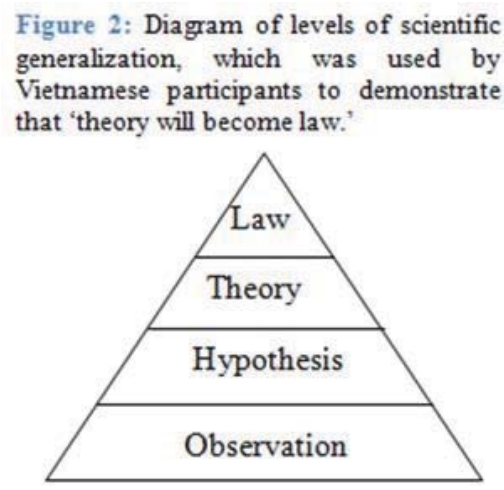

After the discussion, most of the participants agree that theory explain why and law describe how, so they serve different roles in science. However, some participants still not totally agree on the distinction between theory and law and want to keep the idea that 'theory will become law when we have more evidence', even though they cannot find any example to show that there is 'a theory did become a law'. They think that maybe this aspect of nature of science can be changed too as itself has the tentativeness characteristic. We agreed with the idea about the tentativeness of knowledge about NOS, but confirmed that until the present time, it was proved by the history of science, science itself and educators worldwide that laws and theories are two entirely different entities, with different functions and they will never become each other. However, to transform the naïve conception on this NOS aspect, we expected the later NOS professional training workshops should focus on this aspect, with typical examples and demonstrations will be in need.

Lastly, with question Q4-'Can you find some aspects of NOS embedded in your science teaching? What are they? Are they explicit or implicit?' all the participants admit that they teach science, therefore, certainly need to pay regard for some aspects of the nature of science. However, none of the Vietnamese teachers ever taught nature of science explicitly. This is not surprising as nature of science is a very new aspect in Vietnam education and this workshop is the first to introduce and raise the topic. All of them let their students and even themselves implicitly learn about NOS. Some have very positive expectation that their students understand the nature of science well through the implicit approach. However, we use the results from previous activities in which them and the pre-service teachers (their students) made much misconception about nature of science to show them that the implicit approach is not effective, their concern then move to how to teach NOS more effectively.

\section{Conclusion}

Although nature of science in teaching and learning science is a totally new topic in Vietnam, the workshop indicated that most of Vietnamese teachers already have some certain understanding about NOS. Furthermore, they have very positive opinions in teaching NOS as they admitted that science teachers necessarily regard some aspects of NOS in their teaching. We therefore positively think that more researches on Vietnamese NOS notions as well as training workshops should be conducted to help Vietnamese science education shift toward the standard of global education in many countries. Besides using VNOS to collect Vietnamese teachers and students' perceptions of NOS, it is very important to have followed up interview, which should be conducted in an informal manner to help the participants easily represent their own ideas to deal with the context of Vietnamese culture. It is also essential to be repeated here that the function of, and relationship between theories and laws should gain most focus in the next investigations and training programs.

\section{Acknowledges}

The paper was written from workshop that was funded by the project of KKU Science Education Mekong Technology Transfer. This work was also supported by the Higher Education Research Promotion and National Research University Project of Thailand, Office of the Higher Education Commission, through the Cluster of Research to Enhance the Quality of Basic Education 


\section{References}

Dat, N. T., Lap, P. V., Lanh, D. H., and Tuan, M. S. (2007-2012). (Vietnamese) Biology textbook - grade 12: (Vietnamese) Educational Publisher - Ministry of Education and Training.

Goff, P., Boesdorfer, S. B., and Hunter, W. (2012). Using a multicultural approach to teach chemistry and the nature of science to undergraduate non-majors. Cultural Studies of Science Education, 7, 631-651.

Khishfe, R., \& Abd-El-Khalick, F. (2002). Influence of explicit and reflective versus implicit inquiry-oriented instruction on sixth graders' views of nature of science. Journal of Research in Science Teaching, 39(7), 551-578.

Lederman, N. G., Abd-El-Khalick, F., Bell, R. L., and Schwartz, R. e. S. (2002). Views of nature of science questionnaire: toward valid and meaningful assessment of learners' conceptions of nature of science. Journal of Research in Science Teaching, 39(6), 497521.

Lederman, N. G. (2007). Nature of science: Past, present, and future. In S. K. Abell and N. G. Lederman (Eds.), Handbook of Research on Science Education (pp. 831-879). London: Lawrence Erlbaum Associates.

Lederman, N. G., \& Lederman, J. S. (2004). Revising instruction to teach nature of science - modifying activities to enhance student understanding of science. The Science Teacher, November, 36-39.

McComas, W. F. (1996). Ten myths of science: Re-examining what we think we know about theNature of Science. School Science \& Mathematics, 96, 10-16.

McComas, W. F., Almazroa, H., and Clough, M. P. (1998). The nature of science in science education: An introduction. Science and Education, 7(6), 511-532.

Nguyet, T. (2010). Translated from a talk by David Pickus. Sinh viên Việt Nam phải vượt qua "bệnh" thụ động, Vietnam.net. Retrieved from http://vef.vn/2010-12-17-sinh-vien-viet-nam-phai-vuot-qua-benh-thu-dong

Norton, K., Alori, N., Campbell, D., White, R., et al. Science Online - Te Kete Ipurangi: Conflicting theories for the origin of the Moon Retrieved March 2013, from http://scienceonline.tki.org.nz/Nature-of-science/Nature-of-Science-Teaching-Activities/Conflictingtheories-for-the-origin-of-the-Moon

Norton, K., Alori, N., Campbell, D., White, R., et al. Science Online - Te Kete Ipurangi: Establishing priorities for solving problems Retrieved March, 2013, from http://scienceonline.tki.org.nz/Nature-of-science/Nature-of-Science-Teaching-Activities/Establishingpriorities-for-solving-problems

Schwartz, R. S., Lederman, N. G., and Crawford, B. A. (2004). Developing views of nature of science in an authentic context: an explicit approach to bridging the gap between nature of science and scientific inquiry. Science Education, 88(4), 610-645.

SurveyMonkey. Retrieved March, 2013, from https://www.surveymonkey.com/

Thanh, T. (2006). Dạy và học thụ động, đâu là nguyên nhân?, Vietbao.vn. Retrieved from http://vietbao.vn/Giao-duc/Day-va-hoc-thudong-dau-la-nguyen-nhan/75009355/202/

Thao-Do, T. P., Bac-Ly, D. T., and Yuenyoung, C. (2014, in Press). Learning Environment in Vietnamese Physics Teacher Education Programme through the Lens of Constructivism: A Case Study of a State University in Mekong Delta Region, Vietnam. International Journal of Science and Mathematics Education,

Thelllusioncontest. (2010). Impossible motion: magnet-like slopes Retrieved February, 2013, from http://www.youtube.com/watch?v= hAXm0dluyug

TheThinkingAtheist. (2010). You Can't Trust Science! Retrieved February 2013, from http://www.youtube.com/watch?v=KRLR9jhP_DM

Trong, L. X., Cuong, N., and Hien, D. T. (2003-2012). (Vietnamese) Chemistry textbook - grade 8: (Vietnamese) Educational Publisher Ministry of Education and Training. 